\title{
Are Suicide Rates Related to the Psychiatrist Density? A Cross- National Study
}

\author{
Leo Sher*
}

James J. Peters Veterans' Administration Medical Center and Icahn School of Medicine at Mount Sinai, New York, NY, USA

Introduction: Most suicide victims have a diagnosable psychiatric disorder. Treatment of psychiatric disorders should reduce the number of suicides. Higher psychiatristper-population ratio increases the opportunity for contact between the patient and psychiatrist. It is reasonable to hypothesize that the higher psychiatrist density (PD) is associated with lower suicide rates. The aim of this study is to examine the association between suicide rates and the PD in the European Union countries. These countries are economically and culturally connected and located on the same continent. This is an attempt to study a relatively homogenous sample.

Methods: Correlations were computed to examine relationships between agestandardized suicide rates in women and men, the PD, and the gross national income

OPEN ACCESS

Edited by:

Frederick Robert Carrick,

Carrick Institute, USA

Reviewed by:

Rashid Zaman,

University of Cambridge, UK

Ahmed Hankir,

Bedfordshire Centre for Mental Health Research in Association with

Cambridge University, UK

*Correspondence:

Leo Sher

drleosher@gmail.com

Specialty section:

This article was submitted to Child Health and Human Development,

a section of the journal

Frontiers in Public Health

Received: 02 October 2015

Accepted: 10 December 2015

Published: 06 January 2016

Citation:

Sher L (2016) Are Suicide Rates Related to the Psychiatrist Density? A

Cross-National Study.

Front. Public Health 3:280.

doi: 10.3389/fpubh.2015.00280
(GNI) per capita. Partial correlations were used to examine the relation between the PD and age-standardized suicide rates in women and men controlling for the GNI per capita.

Results: Higher suicide rates in women correlated with the higher PD. Controlling for the GNI per capita, the PD positively correlated with suicide rates both in women and in men. There was a trend toward a negative correlation between the GNI per capita and suicide rates in men. The PD was positively associated with the GNI per capita.

Conclusion: Probably, higher suicide rates directly and/or indirectly affect the decisions made by policy- and lawmakers regarding mental health services and how many psychiatrists need to be trained. The results of this study should be treated with caution because many confounding variables are not taken into account.

Keywords: psychiatrist density, gross national income, suicide, European Union, public health

\section{INTRODUCTION}

Suicidal behavior is a major public health issue and a global phenomenon (1-3). Suicide is complex human behavior with multiple causes that include biological and psychosocial components. The World Health Organization (WHO) reports that every year more than 800,000 people take their own life around the world (1). The WHO recognizes suicide as a public health priority. Suicide is an important public health problem in the U.S. In 2013, there were 41,143 suicides in the U.S., which equates to approximately 112 deaths a day (2). Suicide occurs regardless of race, income, or gender. Men die by suicide at a rate four times higher than women. Reductions in suicide burden require multiple actions, including the development of new research programs and new approaches to suicide research and prevention. 
More than $90 \%$ of suicide victims have a diagnosable psychiatric disorder (3-8). The most common psychiatric conditions associated with suicide are mood disorders (3-5). It has been reported that $59-87 \%$ of suicide victims suffer from depression at the time of suicide (4). Personality disorders, alcohol and substance abuse, anxiety disorders, and schizophrenia are also frequently associated with suicide (5-9). Therefore, treatment of psychiatric disorders should reduce the number of suicides.

Higher psychiatrist-per-population ratio improves access, decreases waiting times, and increases the opportunity for contact between the patient and psychiatrist. Generally, an increase in the physician density tends to lead to physician-induced demand (10). People living in countries with greater psychiatrist density (PD) had a higher probability of seeing a psychiatrist.

The literature suggests that availability of good healthcare services may reduce suicide rates by allowing timely identification and appropriate treatment of psychiatric disorders, providing prompt and effective medical help including resuscitation to those who attempt suicide, allowing appropriate management of risk factors for suicides, and facilitating the implementation of national policies on mental health and suicide prevention (11).

It is reasonable to hypothesize that the higher PD is associated with lower suicide rates. To test this hypothesis, I performed an ecological cross-sectional study. I examined the association between suicide rates and the PD in the European Union countries. These countries are economically and culturally connected and located on the same continent. This is an attempt to study a relatively homogenous sample. Socioeconomic factors may influence suicide rates (12-15). Therefore, I controlled for the gross national income (GNI) per capita.

\section{MATERIALS AND METHODS}

Information on age-standardized suicide rates in men and women, the PD, and the GNI per capita in the European Union countries was obtained from the WHO database, "Global Health Observatory Data Repository" (Table 1) (16, 17). The agestandardized suicide rate is a weighted average of the age-specific mortality rates per 100,000 persons, where the weights are the proportions of persons in the corresponding age groups of the WHO standard population (18). The 2012 WHO data on suicide rates were used (16).

The PD is the number of psychiatrists working in the mental health sector per 100,000 of the population (19). Psychiatrists working in mental health include psychiatrists employed in private and public mental health facilities as well as private practice. The most recent data available in the WHO database were used.

TABLE 1 | Age-standardized suicide rates, the psychiatrist density, and the gross national income per capita in the European Union countries.

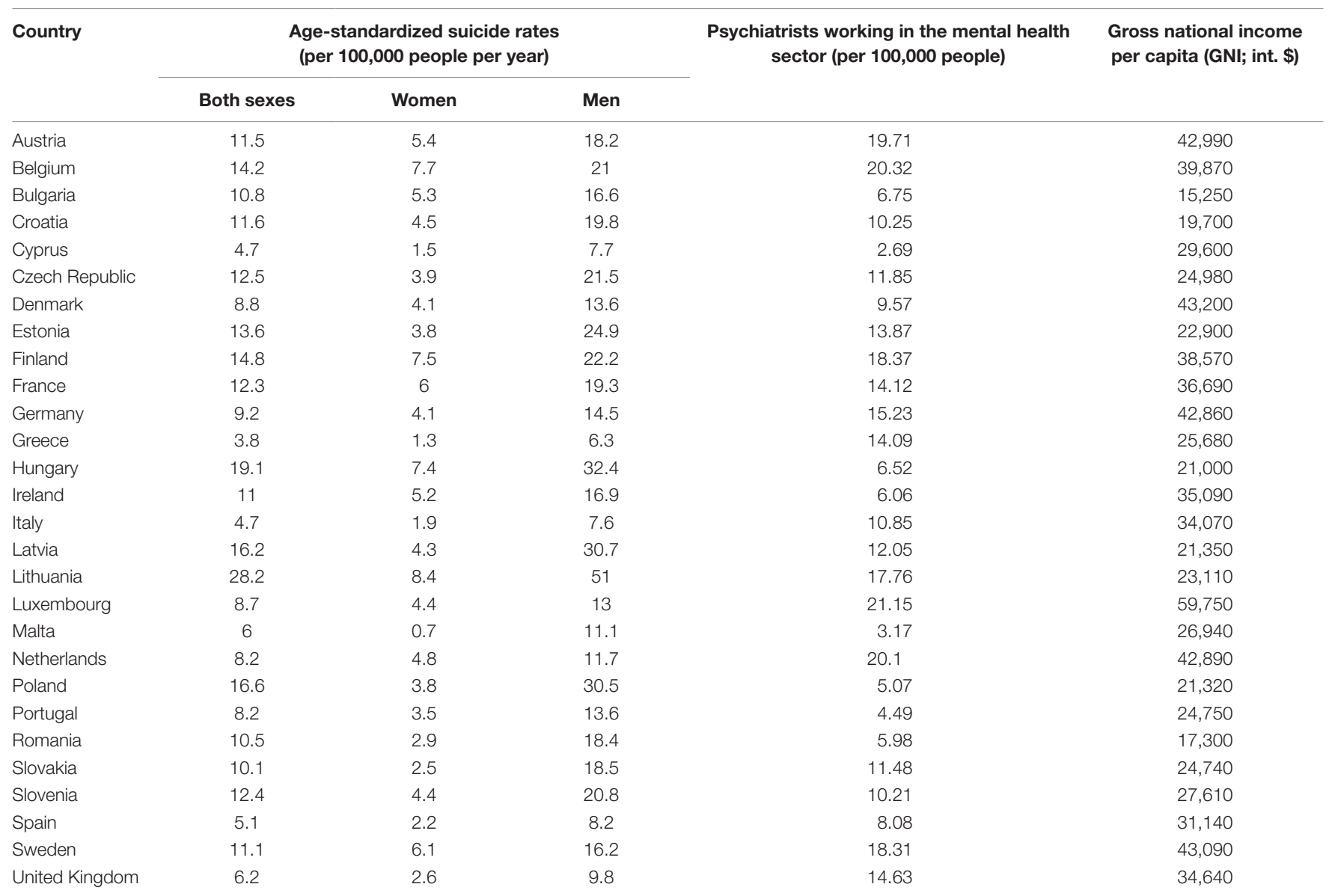


The GNI is the gross national income converted to international dollars using purchasing power parity rates (20). An international dollar has the same purchasing power over the GNI as a U.S. dollar has in the U.S. GNI is the sum of value added by all resident producers plus any product taxes (less subsidies) not included in the valuation of output plus net receipts of primary income (compensation of employees and property income) from abroad. The latest data available in the WHO databank were used.

Correlations were computed to examine relationships between age-standardized suicide rates in women and men, PD, and GNI. Partial correlations were used to examine the relation between

TABLE 2 | Correlations between age-standardized suicide rates, psychiatrist density, and gross national income per capita.

\begin{tabular}{llcc}
\hline Women & Pearson correlation & $\begin{array}{c}\text { Psychiatrist } \\
\text { density }\end{array}$ & $\begin{array}{c}\text { Gross national } \\
\text { income per capita }\end{array}$ \\
\hline & Significance & 0.493 & 0.166 \\
(two-tailed) & 0.008 & 0.4 \\
Men & N & 28 & 28 \\
& Pearson correlation & 0.129 & -0.359 \\
& Significance & 0.514 & 0.61 \\
Psychiatrist & (two-tailed) & & 28 \\
density & Pearson correlation & 28 & 0.633 \\
& Significance & & $<0.001$ \\
& (two-tailed) & & 28
\end{tabular}

PD and age-standardized suicide rates in women and men controlling for GNI.

The following method was used to create scattered plots of partial correlations (21): I created three linear regression models. SNI per capita was an independent variable in every model. In the first, the second, and the third models suicide rates in women, suicide rates in men, and the PD were dependent variables, respectively. I computed the residuals of suicide rates in women, suicide rates in men, and the $\mathrm{PD}$. The partial correlation is equivalent to the correlation between the residuals of the linear regression.

The SPSS program (version 23) was used to perform statistical analysis.

\section{RESULTS}

The WHO have data on all 28 European Union countries included in the study: Austria, Belgium, Bulgaria, Croatia, Cyprus, Czech Republic, Denmark, Estonia, Finland, France, Germany, Greece, Hungary, Ireland, Italy, Latvia, Lithuania, Luxembourg, Malta, Netherlands, Poland, Portugal, Romania, Slovakia, Slovenia, Spain, Sweden, and United Kingdom (Table 1). The mean female and male suicide rates, the PD, and the GNI in the European Union countries were $4.293 \pm 1.992$ and $18.429 \pm 9.413$ per 100,000 people per year, $11.883 \pm 5.605$ per 100,000 people, and $\$ 31,110 \pm 10,374$, respectively.

Higher suicide rates in women correlated with the higher PD (Table 2; Figure 1). Controlling for the GNI per capita, the PD positively correlated with suicide rates both in women and in men

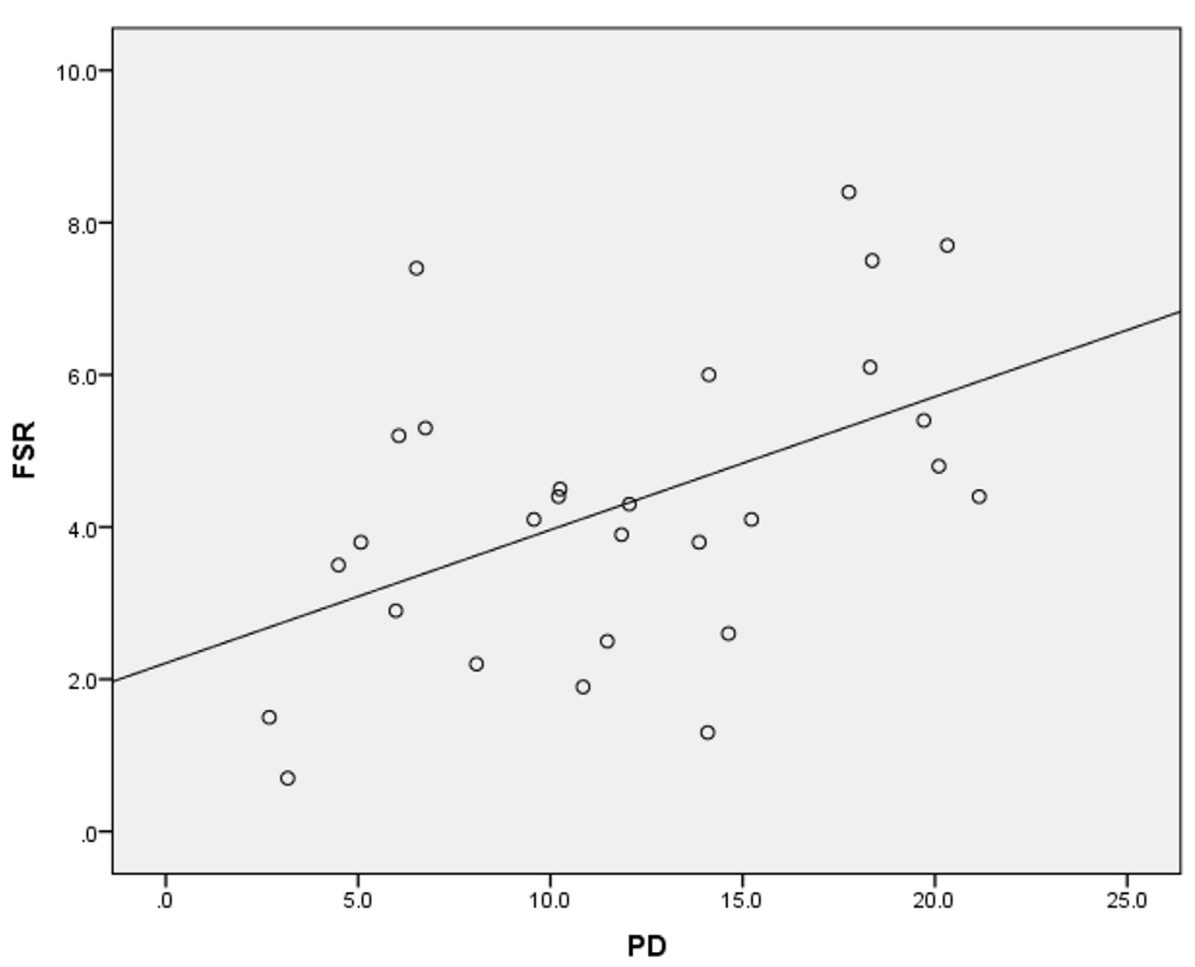

FIGURE 1 | Correlation between psychiatrist density (PD) and female suicide rates (FSR). 
(Table 3; Figures 2 and 3). There was a trend toward a negative correlation between the GNI per capita and suicide rates in men (Table 2; Figure 4). The PD was positively associated with the GNI per capita (Table 2; Figure 5).

\section{DISCUSSION}

\section{Suicide Rates and Psychiatrist Density}

This study suggests that higher suicide rates are associated with higher number of psychiatrists working in mental health per 100,000 people. This observation is consistent with previous reports, suggesting that the $\mathrm{PD}$ positively correlates with suicide rates $(11,22,23)$. The most likely explanation for this association is that the higher suicide rates directly and/or indirectly affect the decisions made by policy- and lawmakers regarding mental health services and how many psychiatrists need to be trained.

TABLE 3 | Correlations between age-standardized suicide rates and psychiatrist density controlling for gross national income (GNI) per capita.

\begin{tabular}{llc}
\hline & & Psychiatrist density \\
\hline \multirow{2}{*}{ Women } & Pearson correlation & 0.508 \\
& Significance (two-tailed) & 0.007 \\
& df & 25 \\
\multirow{2}{*}{ Men } & Pearson correlation & 0.492 \\
& Significance (two-tailed) & 0.009 \\
& df & 25
\end{tabular}

Indeed, there is very considerable evidence that suicide rates may affect national policies related to mental health and suicide prevention (24-28). Also, the registration of suicide cases may be better in countries with a higher PD and higher income (23). This may contribute to the observed association between suicide rates and PD. Additionally, there are the differences between countries with regard to suicide prevention and other mental health services related to the differences in psychiatric education and training (29). This factor may also play a role in the observed associations.

\section{GNI and Suicide Rates in Men}

The presence of a trend toward a negative correlation between the GNI and suicide rates in men is consistent with observations that the economic factors, such as income, wealth, and employment status, may affect suicidality in men (13-15, 30, 31). For example, I have previously observed that per capita income is related to suicide rates in men but not in women: men in countries with lower per capita income commit suicide more frequently than men in countries with higher per capita income (15). Another example is a British study which found that each $10 \%$ increase in the number of unemployed men was significantly associated with a $1.4 \%$ increase in male suicides (31).

\section{Psychiatrist Density and GNI}

This study shows that there is a higher PD in countries with the higher GNI per capita. This is an expected finding: countries with more resources have more physicians, including psychiatrists (11, 22, 23, 32). Median mental health expenditures per capita around

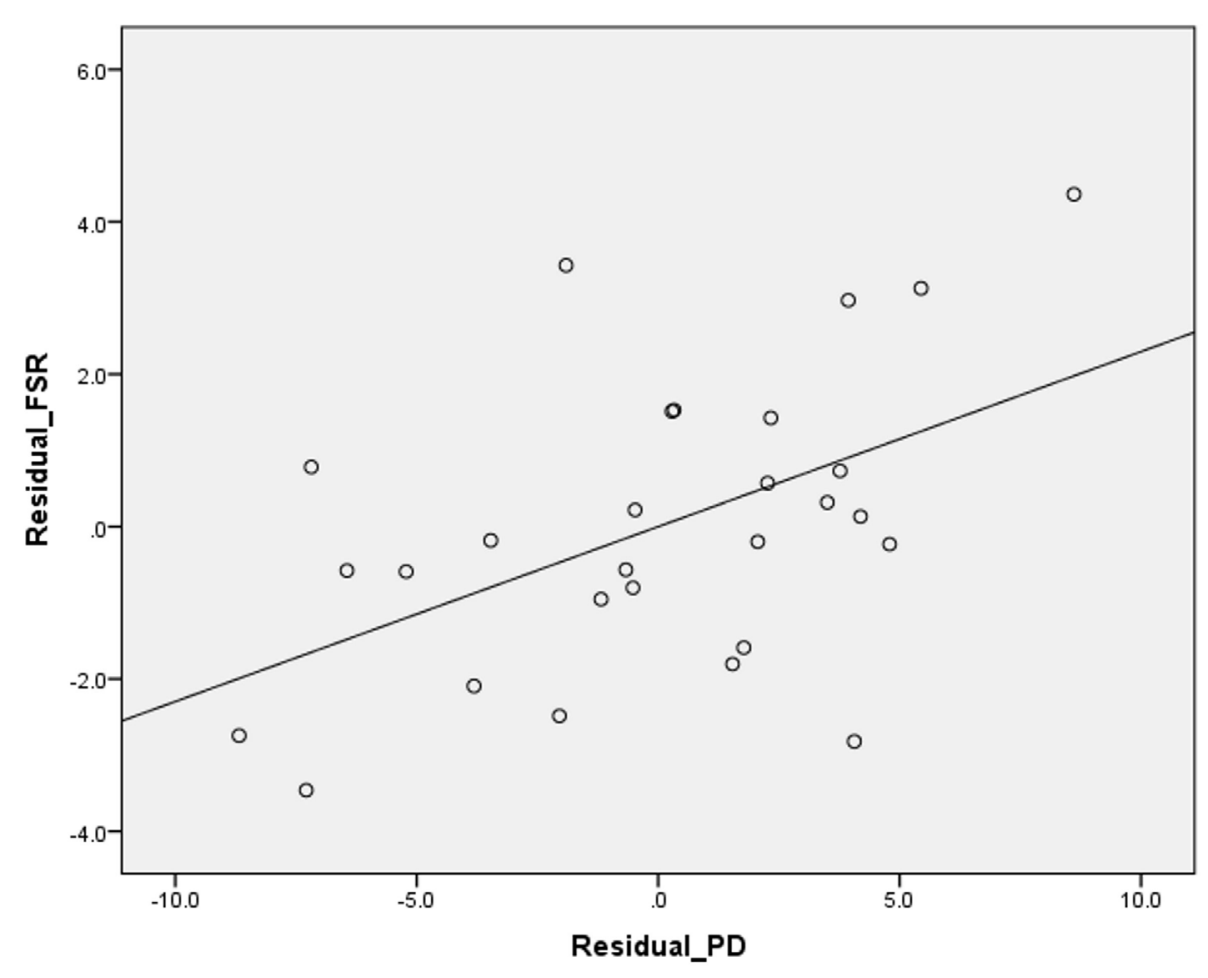

FIGURE 2 | Correlation between the residuals of the psychiatrist density (PD) and female suicide rates (FSR) (equivalent of partial correlation - please, see Materials and Methods). 


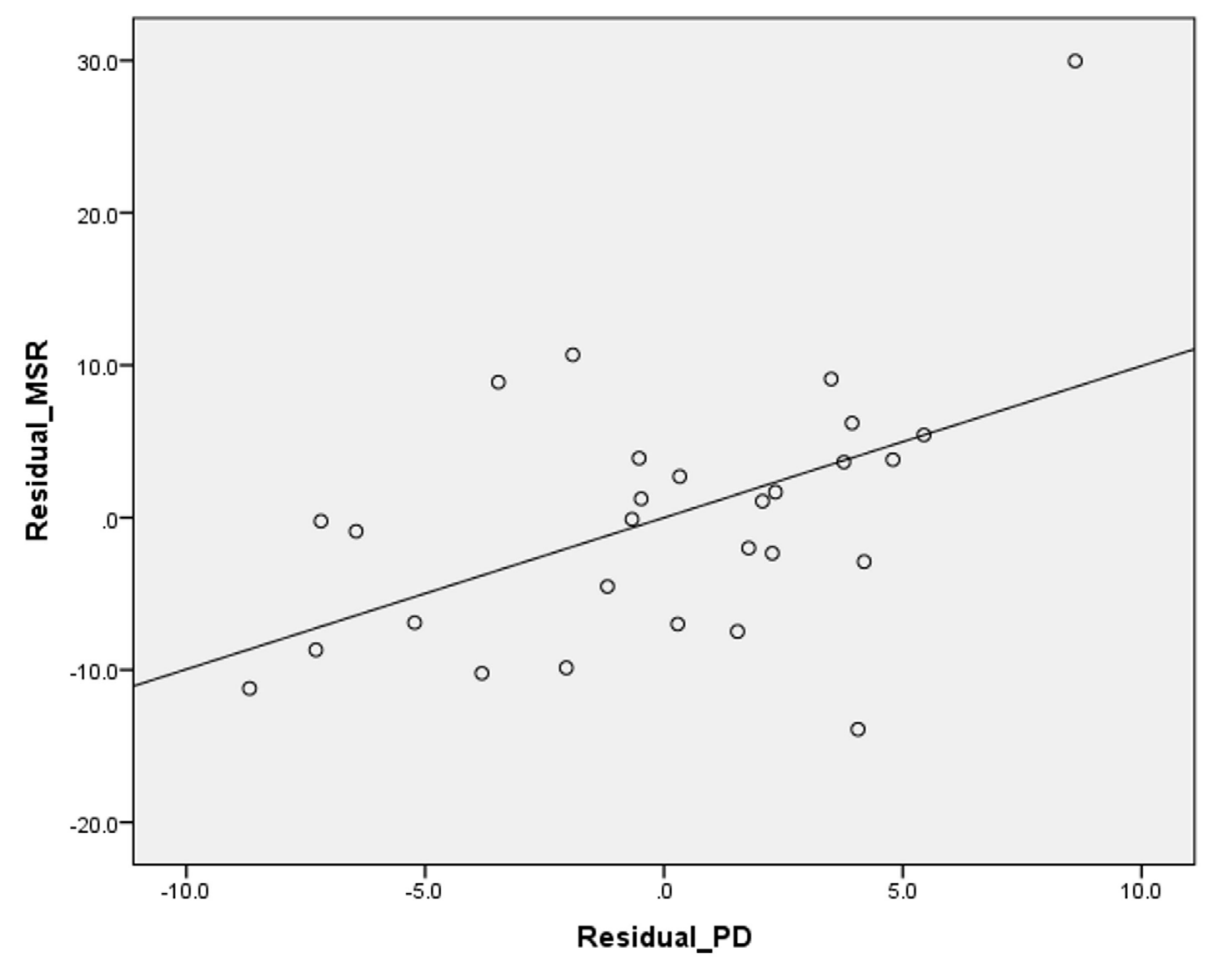

FIGURE 3 | Correlation between the residuals of the psychiatrist density (PD) and male suicide rates (FSR) (equivalent of partial correlation - please, see Materials and Methods).

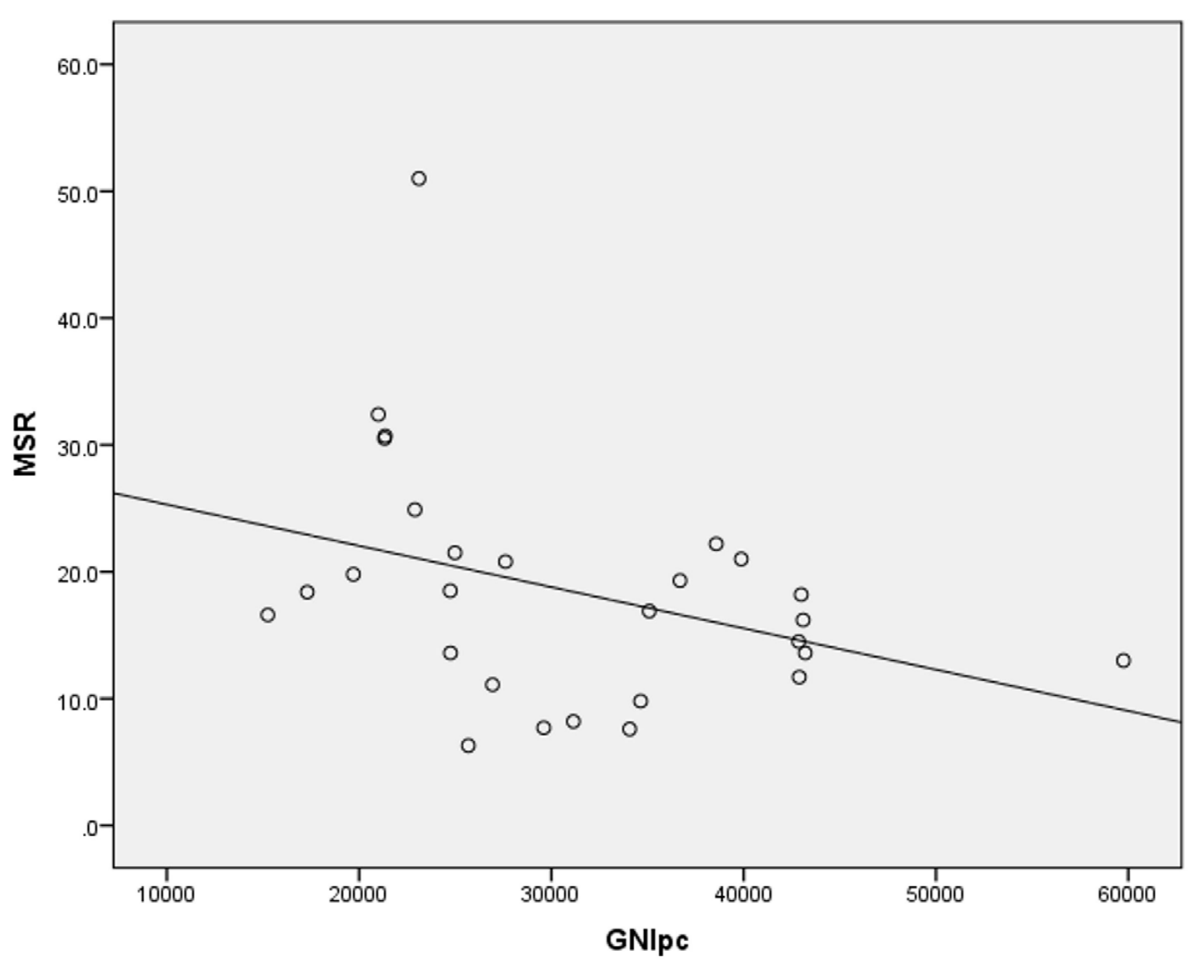

FIGURE 4 | Correlation between the GNI per capita and male suicide rates. 


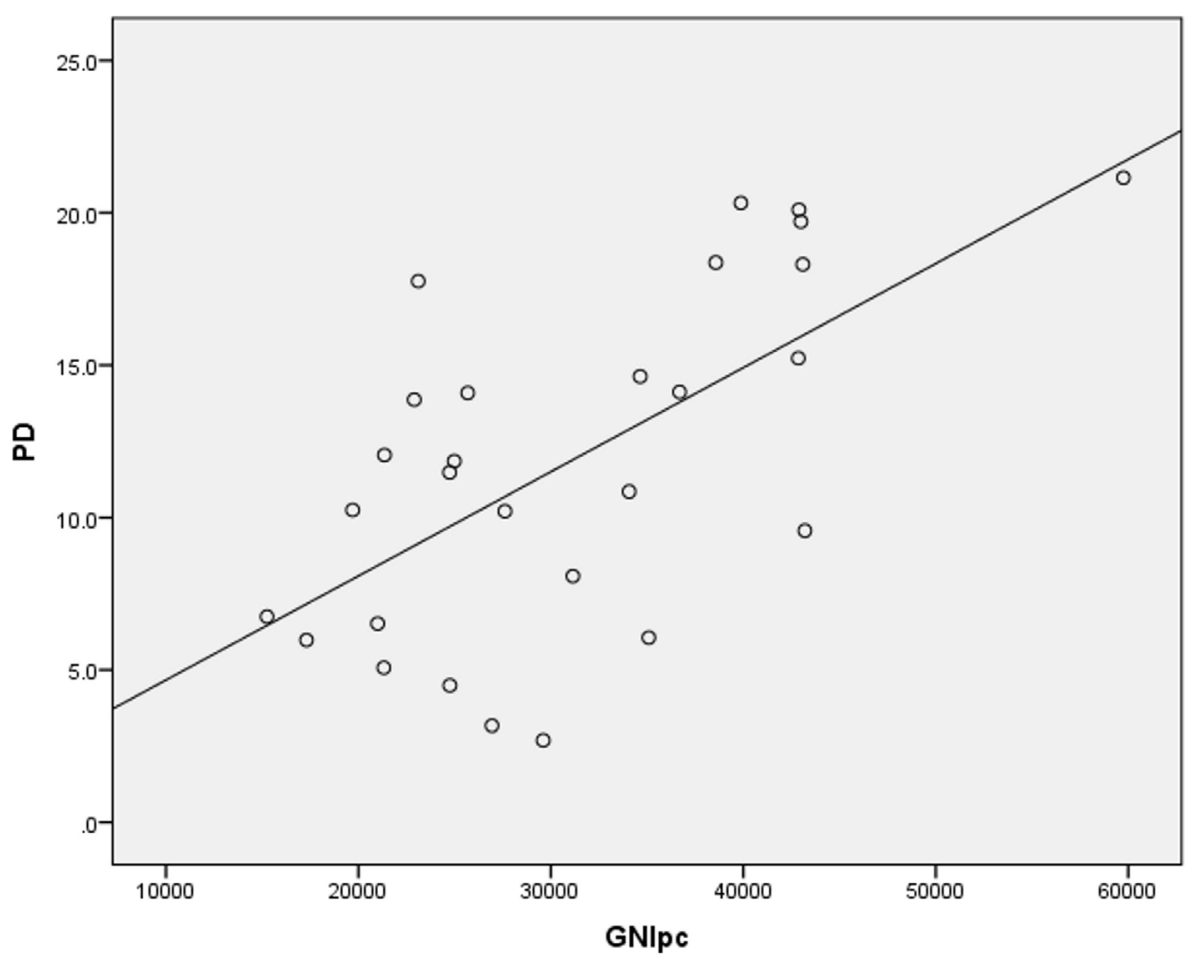

FIGURE 5 | Correlation between the GNI per capita and the psychiatrist density.

the world are $\$ 1.63$ with large variation among income groups, ranging from $\$ 0.20$ in low-income countries to $\$ 44.84$ in high-income countries (32). There is a strong positive correlation between mental health spending per capita and the GNI per capita (32).

\section{Limitations}

The results of this study should be treated with caution because many confounding variables, such as cultural and religious differences between countries have not been taken into account. Also, the quality of training of psychiatrists is probably different in different countries. It is also important to note that the income in the European Union countries is higher than in many other countries. Therefore, the results of this study may not be generalizable to low-income countries.

\section{REFERENCES}

1. World Health Organization. Mental Health. Suicide Data. (2015). Available from: http://www.who.int/mental_health/prevention/suicide/ suicideprevent/en/

2. U.S. Centers for Disease Control and Prevention. National Center for Injury Prevention and Control. Web-Based Injury Statistics Query and Reporting System. Atlanta, GA: CDC (2013). Available from: http://www.cdc.gov/injury/index.html

3. Sher L. Preventing suicide. QJM (2004) 97(10):677-80. doi:10.1093/qjmed/ hch106

4. Rihmer Z. Can better recognition and treatment of depression reduce suicide rates? A brief review. Eur Psychiatry (2001) 16(7):406-9. doi:10.1016/ S0924-9338(01)00598-3

5. Sher L, Oquendo MA, Mann JJ. Risk of suicide in mood disorders. Clin Neurosci Res (2001) 1:337-44. doi:10.1016/S1566-2772(01)00035-4

\section{CONCLUSION}

Both mental health services and socioeconomic improvements are needed to reduce suicide rates. Probably, psychiatric services prevent many suicides. Absence of suicide produces no data. It is difficult to notice successful suicide prevention. Future epidemiological, ecological, psychological, and neurobiological studies of suicidality are merited and may lead to the development of treatments which will reduce suicide rates.

\section{AUTHOR CONTRIBUTIONS}

LS has designed the study, conducted literature searches and statistical analysis, and wrote the manuscript.

6. Mann JJ. A current perspective on suicide and attempted suicide. Ann Intern Med (2002) 136:302-11. doi:10.7326/0003-4819-136-4-200202190-00010

7. Hirschfeld RM, Russell JM. Assessment and treatment of suicidal patients. $N$ Engl J Med (1997) 337:910-5. doi:10.1056/NEJM199709253371307

8. Mann JJ. Neurobiology of suicidal behavior. Nat Rev Neurosci (2003) 4:819-28. doi: $10.1038 / \mathrm{nrn} 1220$

9. Sher L. Alcoholism and suicidal behavior: a clinical overview. Acta Psychiatr Scand (2006) 113(1):13-22. doi:10.1111/j.1600-0447.2005.00643.x

10. Léonard C, Stordeur S, Roberfroid D. Association between physician density and health care consumption: a systematic review of the evidence. Health Policy (2009) 91(2):121-34. doi:10.1016/j.healthpol.2008.11.013

11. Shah A, Bhandarkar R, Bhatia G. The relationship between general population suicide rates and mental health funding, service provision and national policy: a cross-national study. Int J Soc Psychiatry (2010) 56(4):448-53. doi:10.1177/0020764009342384 
12. Jalles JT, Andresen MA. The social and economic determinants of suicide in Canadian provinces. Health Econ Rev (2015) 5:1. doi:10.1186/ s13561-015-0041-y

13. Milner A, McClure R, De Leo D. Socio-economic determinants of suicide: an ecological analysis of 35 countries. Soc Psychiatry Psychiatr Epidemiol (2012) 47(1):19-27. doi:10.1007/s00127-010-0316-x

14. Neumayer E. Socioeconomic factors and suicide rates at large-unit aggregate levels: a comment. Urban Stud (2003) 40:2769-76. doi:10.1080/0042098032 000191029

15. Sher L. Per capita income is related to suicide rates in men but not in women. J Mens Health Gender (2006) 3:39-42. doi:10.1016/j.jmhg.2005.04.016

16. World Health Organization. Global Health Observatory Data Repository. Suicide Rates. Data by Country (2015). Available from: http://apps.who.int/ gho/data/view.main.MHSUICIDEv

17. World Health Organization. Global Health Observatory Data Repository. Browse Data Tables by Country (2015). Available from: http://apps.who.int/ gho/data/node.country

18. World Health Organization. Age-Standardized Mortality Rate (per 100000 Population) (2011). Available from: http://apps.who.int/gho/indicatorregistry/App_Main/view_indicator.aspx?iid=78

19. World Health Organization. Psychiatrists Working in Mental Health Sector, per 100,000 (2011). Available from: http://apps.who.int/gho/indicatorregistry/ App_Main/view_indicator.aspx?iid=2954

20. World Health Organization. Gross National Income per Capita (PPP int. \$) (2011). Available from: http://apps.who.int/gho/indicatorregistry/App_Main/ view_indicator.aspx?iid $=94$

21. Moya-Laraño J, Corcobado G. Plotting partial correlation and regression in ecological studies. Web Ecol (2008) 8:35-46. doi:10.5194/we-8-35-2008

22. Burgess P, Pirkis J, Jolley D, Whiteford H, Saxena S. Do nations' mental health policies, programs and legislation influence their suicide rates? An ecological study of 100 countries. Aust N Z J Psychiatry (2004) 38(11-12):933-9. doi:10.1080/j.1440-1614.2004.01484.x

23. Rajkumar AP, Brinda EM, Duba AS, Thangadurai P, Jacob KS. National suicide rates and mental health system indicators: an ecological study of 191 countries. Int J Law Psychiatry (2013) 36(5-6):339-42. doi:10.1016/j. ijlp.2013.06.004
24. Chiu HFK, Takahashi Y, Suh GK. Elderly suicide prevention in East Asia. Int J Geriatr Psychiatry (2003) 18:973-6. doi:10.1002/gps.923

25. Shah AK. The importance of socio-economic status of countries for mental disorders in old age: a development of an epidemiological transition model. Int Psychogeriatr (2007) 19:785-7. doi:10.1017/S1041610207005479

26. Taylor SJ, Kingdom D, Jenkins R. How are nations trying to prevent suicide? An analysis of national suicide prevention strategies. Acta Psychiatr Scand (1997) 95:457-63. doi:10.1111/j.1600-0447.1997.tb10132.x

27. Beautrais A, Fergusson D, Coggan C, Collings C, Doughty C, Ellis P, et al Effective strategies for suicide prevention in New Zealand: a review of the evidence. NZ Med J (1251) 120:U2459.

28. U.S. Department of Health and Human Services (HHS); Office of the Surgeon General ; National Action Alliance for Suicide Prevention. 2012 National Strategy for Suicide Prevention: Goals and Objectives for Action. Washington, DC: HHS (2012)

29. Zisook S, Balon R, Björkstén KS, Everall I, Dunn L, Ganadjian K, et al. Psychiatry residency training around the world. Acad Psychiatry (2007) 31(4):309-25. doi:10.1176/appi.ap.31.4.309

30. Walsh BM, Walsh D. Suicide in Ireland: the influence of alcohol and unemployment. Econ Soc Rev (2001) 42(1):27-47.

31. Barr B, Taylor-Robinson D, Scott-Samuel A, McKee M, Stuckler D. Suicides associated with the 2008-10 economic recession in England: time trend analysis. BMJ (2012) 345:e5142. doi:10.1136/bmj.e5142

32. Morris J, Lora A, McBain R, Saxena S. Global mental health resources and services: a WHO survey of 184 countries. Publ Health Rev (2012) 34(2):1-19.

Conflict of Interest Statement: The author declares that the research was conducted in the absence of any commercial or financial relationships that could be construed as a potential conflict of interest.

Copyright (c) 2016 Sher. This is an open-access article distributed under the terms of the Creative Commons Attribution License (CC BY). The use, distribution or reproduction in other forums is permitted, provided the original author(s) or licensor are credited and that the original publication in this journal is cited, in accordance with accepted academic practice. No use, distribution or reproduction is permitted which does not comply with these terms. 